\title{
A ATUALIDADE DOS DEZ PRINCÍPIOS DA MAFALDA DE "QUINO" PARA UMA EDUCAÇÃO ÉTICA E DA RAZÃO CRIATIVA
}

\author{
THE ACTUALITY OF MAFALDA'S TEN PRINCIPLES BY "QUINO" FOR AN \\ ETHICAL AND A CREATIVE-REASON EDUCATION
}

\author{
Luzia Batista De Oliveira Silva ${ }^{1 *}$, Nilo Agostini ${ }^{2}$ \\ ${ }^{1}$ Pós-doutorada em Antropologia/Ciências Sociais pela PUC/SP, Programa de Pós-Graduação Stricto Sensu em Educação - \\ PPGSSE/USF, Bragança Paulista, SP, Brasil, e-mail \\ ${ }^{2}$ Pós-doutorado em Educação pela Universidade Federal de São Carlos, SP, Programa de Pós-Graduação Stricto Sensu em Educação \\ - PPGSSE/USF, Bragança Paulista, SP, Brasil, e-mail \\ ${ }^{*}$ Autor de correspondência
}

\section{Resumo}

Objetiva-se discutir nesse artigo a atualidade dos Dez princípios da Mafalda, como princípios norteadores de uma ética e uma razão criativa na infância, uma contribuição de "Quino" - Joaquín Salvador Lavado Tejón (1968) para a Educação. Esses Dez princípios são relevantes no aprendizado coletivo das crianças e no processo de sensibilização dos adultos. As críticas ao mundo do adulto são críticas de uma personagem criança, envolvida nas discussões diárias, nos problemas e dilemas dos adultos, causados por eles mesmos. Destaca-se valores como fundamentais nos dez princípios: direito à vida de criança cidadã, respeito ao ser humano e à criança e sua infância, direito ao cuidado, à inserção social, cultural e educacional, proteção, cidadania, direito para expressar criatividade e curiosidade, obter conhecimento de saberes com qualidade para garantir emancipação e autonomia, educar-se sem constrangimentos, discriminação, preconceito de classe, étnico, cultural, aprender a cultivar valores pessoais e coletivos sem imposição e sem dogmatismo. Enfim, Quino parece assinalar para uma educação que preze por uma construção de conhecimentos de modo aberto e que o despertar da curiosidade e da razão criativa sejam valorizados no processo formativo, um processo de mimesis, de troca e de revide entre as crianças e os adultos. A infância em Quino permite discutir sobre comportamentos sociais e educação ética mediante exercícios e posicionamentos críticos e criativos respaldados por uma sensibilidade e uma razão criativa, como elementos formadores e norteadores de uma educação para o pensar e para a valorização da vida.

Palavras-chave: Criança. Educação. Sensibilidade. Princípios. Razão criativa.

\begin{abstract}
It aims to discuss in this article the actuality of Mafalda's Ten Principles (Os Dez Princípios de Mafalda), as guiding principles of an ethics and a creative reason in childhood, a contribution by "Quino" - Joaquín Salvador Lavado Tejón (1968) to Education. These Ten Principles are relevant to children's collective learning and to the adult sentitize process. The criticism of the adult world are critics by a child character, involved in the daily discussions, problems, and dilemmas of adults caused by themselves. It stands out as fundamentals values in the ten principles: right to a citizen child life, respect for the human being and for the child and its childhood, right to care, right to social, cultural and educational insertion, right to protection and citizenship, right to express creativity and curiosity, right to get knowledge of a quality education to ensure emancipation and autonomy, right to be able to educate oneself without constraints, discrimination, and class, ethnical or cultural prejudice, learning to cultivate personal and collective values without imposition and without dogmatism. Anyway, Quino seems to point to an education that values knowledge building in an open way, and also that the awakening of curiosity and creative reason are valued in the formative process, a process of mimesis, of exchange and discussion between children and adults. The childhood for Quino allows
\end{abstract}


us to discuss social behaviors and ethical education through critical and creative exercises and positions supported by a sensibility and a creative reason, as forming and guiding elements of an education for thinking and valuing life.

Keywords: Child. Education. Sensitivity. Principles. Creative reason.

CUNIS-MG. All rights reserved.

How to cite this article:

SILVA, Luzia Batista De Oliveira Silva; AGOSTINI, Nilo. A ATUALIDADE DOS DEZ PRINCÍPIOS DA MAFALDA DE “QUINO” PARA UMA EDUCAÇÃO ÉTICA E DA RAZÃO CRIATIVA. Interação, Varginha, MG, v. 21, p. 32, 2019. ISSN 1517-848X / ISSN 2446-9874.

Disponível em: http://periodicos.unis.edu.br/index.php/interacao/article/view/198/172

DOI: https://doi.org/10.33836/interacao.v21i1.198 (editoração da revista)

\section{INTRODUÇÃO}

A palavra princípio vem do latim (principium), em Filosofia significa ponto de partida, fundamento ou causa de uma coisa, aquilo dá início, a causa primeira ou o que fundamenta uma ideia, um sistema, uma tese, um conhecimento específico, um fenômeno; é portanto, um "ponto de partida e fundamento de um processo qualquer" (ABBAGNANO, 2000, p. 792). Na obra de Tejón (1977), os dez princípios norteiam uma educação ética e estética no que tange aos direitos cidadãos da criança e sua infância. Dizem respeito ao direito da criança de ser criança e ter uma infância cercada de cuidados, proteção, educação e incentivo para exercer sua cidadania de maneira livre e assertiva, sem impedimentos ideológicos ou humanos, sem distinção de classe social ou de etnia.

Por isso, objetivou-se discutir nesse artigo sobre a Declaracion de los direchos del niño ou, os Dez princípios da Mafalda, e sua atualidade, como sendo princípios norteadores de uma ética e uma razão criativa na infância, uma contribuição de "Quino" - Joaquín Salvador Lavado Tejón (1977) para a Educação.

O artigo é parte de uma pesquisa sobre a perspectiva da criança, da infância e da educação. Os princípios ético-estéticos apontados pelo artista argentino são relevantes no aprendizado individual e coletivo das crianças e adultos e no processo de sensibilização das crianças e dos adultos.

Quino nos oferece um caminho para um processo de mimesis, cuja categoria em Walter Benjamin aponta para aquilo que nos dá significados, representações e receptividades (BENJAMIN, IN: SCHOLEM, 1989), constituindo-se numa de troca e revide de sentimentos e palavras entre as crianças e os adultos. A infância em Quino permite discutir sobre comportamentos sociais e educação ético-estética mediante exercícios e posicionamentos críticos e criativos respaldados por uma sensibilidade e uma razão criativa, como elementos formadores e norteadores de uma educação para o pensar e para a valorização da vida.

Discute-se inicialmente, sobre a vida e obra de Quino; depois, apresenta-se os dez princípios, ancorados por uma leitura filosófico-educativa, sob a questão ético-estética na obra do artista criador da personagem em quadrinhos, Mafalda. 


\section{VIDA E OBRA DE QUINO}

Quino é um apelido carinhoso da família de Joaquín Salvador Lavado Tejón, nascido em 1932, com a finalidade de distinguir o tio desenhista do sobrinho que também se tornou desenhista, um talentoso crítico e artista argentino. O tio lhe serviu de inspiração na arte do desenho. Quino é filho de pais espanhóis da cidade de Andaluzia na Espanha. Quino nasceu na cidade de Mendonza na Argentina e nela cresceu, trabalhou e criou sua arte com muita sensibilidade e perspicácia crítica objetivando colocar a criança, através de seus personagens infantis, no centro das questões e das inquietações dos adultos, a criança em franco diálogo e enfrentamento. Na sua cidade natal, ele buscou inspiração para viver, para sonhar e para criar personagens que pudessem reivindicar o brincar na infância, que pudessem dizer, desdenhar e satirizar o mundo do adulto em meio aos dramas e atropelos cotidianos.

Quino ficou órfão muito cedo, primeiro foi a perda da mãe aos treze anos de idade e depois de três anos, também perdeu o pai. Entrou na Faculdade de Belas Artes de Mendonza ainda muito jovem, mas anos depois a abandona para se dedicar a arte do desenho. Profissionalmente, iniciou a carreira de desenhista de animação, mas enfrentou muitas dificuldades para se colocar e sobreviver no acirrado mercado da arte.

O desenhista que filosofava enquanto criava sua arte, criou uma menina que filosofa com arte, e nos surpreende pela sua maneira irônica, sábia e criativa, uma menina de espírito debochado e que pensa de maneira rigorosa. Mafalda é por isso, um misto de filósofa e anarquista da vida. A personagem criança retrata com fidelidade a postura política e ácida do desenhista para com a sociedade transgressora. Mafalda coloca o dedo na ferida e faz doer e pensar as consciências indiferentes e despreocupadas com os dramas da criança no mundo.

Atualmente, é preocupante a situação de milhares de crianças que passam fome, sede e sofrem com as guerras, desabrigos, abandonos, cuja vulnerabilidade infantil tornou-se uma questão ética emergencial para governos do mundo inteiro. Acentuam-se cada vez mais os casos de maus tratos, de assédio moral, de violência, de morte, de abandono, de exploração, de pedofilia, que chamam nossa atenção e das mídias e sites de relacionamento.

Por que diante de todo aparato tecnológico e científico que dispomos hoje, com informações que cruzam mares e derrubam fronteiras, ainda não conseguimos proteger nossas crianças carentes, nem aquelas que parecem fora de suspeita?

É assustador tomar conhecimento de casos e mais casos, longe e perto de nós daquelas que estão na linha da morte, que perderam a esperança antes mesmo de tê-la conquistado, famílias divididas, pais ocupados demais com a sobrevivência, escolas que não educam como deveriam, sociedade que não é exemplo para as crianças, pais que matam cada vez mais, adultos que escravizam crianças, crianças tratadas como animais de estimação.

Avançamos em conhecimento sobre a infância e a vida do ser criança, mas não avançamos no que tange às questões éticas porque na vida prática não se pode assegurar uma prática ética, como ela é expressa em documentos fundamentais em qualquer sociedade, se as ações não forem guiadas para isso.

Pode-se julgar e condenar através da Lei, abusos, violações, mas é imprescindível compreender que uma educação ética pode ser um elemento valioso para orientar práticas cotidianas, dado que não é suficiente garanti-la apenas nos documentos, na Lei, na Constituição, nos Estatutos, nos códigos de ética, nas normas, nos discursos, nos diálogos e nas pesquisas e reflexões de pesquisadores sobre o assunto. 
É fundamental garantir uma educação ética, e não se trata de uma educação moral ou moralizante, é justamente porque a ética é também ethos - destarte, uma sociedade precisa proteger, abrigar, amparar as crianças, respaldar as ações das pessoas mediante uma propositura ética que se possa ensinar, uma ética que opere nas relações dos seres humanos com outros seres humanos e com o mundo.

Uma educação ética nos moldes de Paulo Freire (2014), por exemplo, é uma proposta de uma educação prática, colocando a ética como elemento relevante no embasamento de ações cotidianas, uma educação que ensina o valor da indignação contra as injustiças do mundo, fundamental para a criança pobre quanto para a criança rica, porque todos são sujeitos do mundo e no mundo.

Freire (2014, p. 34) pontua duas formas erradas de lidar com a criança, a primeira é “A tirania da liberdade" - educar sem colocar limites para as crianças, ser conivente com a falta de educação e grosseria das crianças ou até mesmo tomar uma atitude de covardia e não chamar a atenção da criança, o que pode revelar insegurança ou carência do adulto, e "A tirania do autoritarismo" - educar colocando as regras acima de tudo, com prevalência do autoritarismo na relação com a criança, que pode revelar agressividade, violência e subjugação.

É fundamental para Freire (2014), que possamos fugir da tentação de um racionalismo agressivo (racionalismo exacerbado), para saber comunicar e interligar as coisas pela inteligência, pela razão criativa, que tem tudo a ver com o processo de aprendizado e descoberta de mundo da criança. Envolver a criança numa leitura de mundo (p.42), competindo ao adulto, saber ouvir, saber compreender, saber identificar os sinais da criança, para interligar, comunicar, denunciar, anunciar, fazer conjecturas sobre um projeto de mundo, um projeto de ação política, em que uma educação ético-política seja a base para uma educação formativa dos valores subjetivos e objetivos.

Mafalda encarna por isso, a criança que lembra ao adulto que ela está em fase de crescimento, de descoberta de mundo, de leitura de mundo (FREIRE, 2013), fase de muita curiosidade, de formação escolar e humana, o que significa que não é um ser humano sem formação e nem sem conhecimento. De maneira cotidiana a personagem se coloca no mundo do adulto para dialogar com o adulto, especialmente quando as decisões do adulto contrariam sua opinião e revelam a contradição entre o que fazem, o que dizem, o que sustentam e o que praticam quando se relacionam com as crianças.

Quino cria a personagem Mafalda e vai moldando-a e gestando-a durante seu trabalho como fotógrafo publicitário. A obra o "Mundo Quino" de 1963 traz uma coleção de sua produção artística com quadrinhos humorísticos mudos, e marca o seu nome no mundo da arte. Suas coleções de livros ganharam territórios para além dos muros de Buenos Aires e foram editadas na Itália, na França e Portugal. Suas páginas de humor gráfico, as tirinhas ganharam espaço em jornais internacionais. $O$ artista desenhou a Mafalda até os anos 70, depois criou outras tirinhas e também outros personagens.

Pode-se afirmar que a obra de Quino é atualíssima, o que por um lado é triste, triste porque estamos discutindo as mesmas questões dos anos setenta, oitenta e noventa, por outro lado, um grande autor deixa sempre uma lição imorredoura, Mafalda é por isso, a porta-voz das crianças, a criança interior de Quino e de muitas pessoas que continuam a cultivar a velha e boa rebeldia, a capacidade de revidar contra as tiranas mundanas, os abusos de autoridade, os poderes pobres dos que se sentem inatingíveis no mundo, a incapacidade humana para agir eticamente, protegendo-se como ser humano e como cidadão do mundo e de proteger aos que 
ama e aos que não ama e nem tem uma relação direta, por entender que todos os seres humanos têm direitos e deveres, que todos somos partes de um todo, a humanidade.

Ensinar às crianças a ler o mundo, como nos orienta Paulo Freire (2013), como uma leitura crítica (FREIRE, 2014, p. 42), porque é parte de "um que-fazer-pedagógico-político indicotomizável do que-fazer político-pedagógico, ação para organizar grupos capazes de intervir na reinvenção da sociedade".

Operar nesse sentido ético é fundamental a fim de mudar a nossa compreensão sobre o que se pode extrair de uma experiência cultural, uma experiência com uma "educação crítica, radical", ter percepção da mudança e da natureza dessa mudança, identificar os elementos e valores da política e os valores ideológicos, destarte, qual a posição que tomamos no mundo e com o mundo? Qual o gosto estético da criança e como ela faz leitura das artes, da música? E finalmente, que valores estéticos estão presentes hoje no cotidiano das crianças?

Quino recebeu vários reconhecimentos internacionais, medalhas e homenagens como a da França, da Ordem Oficial da Legião de Honra, uma distinção mais que esperada pelos estrangeiros, do governo da França. Mafalda ficou conhecida em dezenas de países e figurou em dezenas de exposições pelo mundo. Quino recebeu dezenas de homenagens por sua personagem mais internacional. Ela é a menina filósofa que curte música de qualidade, como a música dos Beatles, compartilha a ideia de um mundo democrático, defende-se como criança e em nome das crianças reivindica uma educação para a prática da liberdade, defende os direitos das crianças de serem bem tratadas e serem uma voz entre os adultos, defende o direito à leitura de obras e mundo, ou seja, o direito de instruir-se como parte da cidadania, se posicionar em nome da paz e gostar de massas, como as de panquecas, odiar a discriminação, a manipulação de seres humanos por outros seres humanos e a guerra. Mafalda passou dos cinquenta anos desde sua criação por Quino, mas continua no imaginário dos que acompanharam a sua obra e das gerações mais jovens, que a descobre e se surpreendem.

A sensibilidade do artista criador da Mafalda é a mesma que o faz chorar por causa das guerras que destroem as crianças, os inocentes, por causa da fome e da sede que assolam o mundo na atualidade, por causa da desigualdade que impera soberana, acirrada e cultuada no altar das loucuras e dos altares capitalistas, como afirma Benjamin (2013) na obra O Capitalismo como religião.

Nas palavras de Leila Guerriero (2014), Quino foi "educado em meio a lutos e guerras, parece mover-se entre uma sensibilidade ardente pelo sofrimento dos fracos e uma repulsa escancarada por qualquer tipo de poder". E parece que não poderia ser diferente, diante de tudo o que viveu e superou e que ainda vive, numa sociedade que persiste em rotular e mais grave, negligenciar o direito da criança de ser criança, viver, pensar e aprender como uma criança.

Guerriero (2014) insiste sobre a sua vida e a criação de seus personagens, questiona sobre como o artista trabalha a contradição social entre os que são poderosos e lembra o artista e sua biografia no site criado, de maneira sintomática quando nos presenteia com a seguinte frase: “[...] e, em 1964, nasce Mafalda, uma menina que tenta resolver o dilema de quem são os bons e quem são os maus neste mundo". Um dilema para além de qualquer maniqueísmo - numa difícil e inusitada missão...

Um dilema que nos fere, seja como educador, como pais humanos, como cidadãos, como viventes, como sobreviventes de guerra, como trabalhadores na luta gigantesca para garantir o pão sobre a mesa, as lutas cotiadas dos refugiados do mundo, dos chamados refugos humanos (BAUMAN, 1998). O que parece no sentido de Freire (2014, p. 9), nos fazer querer buscar 
elementos utópicos, tal como o de democratizar uma sociedade pelo "amor-indignaçãoesperança". E jamais desistir de lutar, porque a desistência de lutar por uma educação e sociedade ética e democrática é desistir de lutar por justiça, por liberdade, é ignorar a relação opressor versus oprimido, a luta pela polis como uma luta política (p.41).

Para ver e ouvir a criança na atualidade faz-se fundamental uma sensibilidade no que tange aos seus direitos e sua aprendizagem tanto numa educação formal quanto numa educação não formal / informal.

Quino comenta com a jornalista Leila Guerriero (2014) sobre sua infância e sua timidez: “Mendoza era o Mediterrâneo: todos eram sírio-libaneses, italianos, espanhóis. O verdureiro, o fruteiro. Eu falava como meus pais em andaluz. Aí no colégio foi terrível, porque ninguém me entendia..." E continua a descrever esta mistura de povos na cidade de Mendoza e das dificuldades de se fazer entender: "Eu dizia "esse tío", no sentido que se dá na Espanha à palavra tío [equivalente a "esse cara" no Brasil], e me perguntavam se fulano era meu tio. Era tímido demais, e como não me entendiam era pior". Sua timidez o silenciou em certas situações, mas não o impediu de criar uma obra artística e genial como o pensamento crítico de uma criança em formação - Mafalda.

Nessa entrevista, comentar a respeito de sua memória da infância com os seus pais, confessa que em sua opinião eles eram bons pais, no entanto, suas lembranças lhe pareciam espantosas sobre os mesmos. Rememora a cena em que sua mãe agonizou por dois anos em consequência de um câncer, depois, quando seu pai repentinamente morre de infarto. Também comenta sua predileção por usar roupa preta, usar gravatinha e não poder ouvir rádio porque estava de luto, e este durava três pesados anos. Comenta também que ele tinha muito medo de certas figuras humanas, como as de idosos porque a velhice lhe assustava, por exemplo, seu avô o assustava, depois pondera que na verdade a velhice parece que nos faz perder a autonomia, a agilidade e ganhar em chatice, talvez seja este o seu maior temor, o de perder alguma coisa valiosa. Também confessa que tinha medo de bêbados e ao que parece também medo de pessoas loucas: "Tinha medo dos velhos. E dos bêbados. Eles me aterrorizavam. Numa noite de verão, a campainha da sala tocou, eu fui abrir a porta e me deparei com uma mulher desgrenhada, com um cano na mão, que me disse: 'O doutor Schiudice me proibiu o vinho'...". Tenta se justificar e diz: "Levei tamanho susto que fechei com chave e fui correndo para o fundo. Havia um hospital psiquiátrico em Mendoza, e esse doutor era o diretor. Foi um dos maiores sustos que levei na minha vida". (GUERRIERO, 2014)

Aos 18 anos de idade, Quino se engajou nos desenhos de "humor mudo" no qual seus personagens que faziam chistes sobre militares, como em Mafalda e "o pauzinho de amassar ideologias" e também sobre casais e religião.

O artista viveu por um tempo numa pensão, dividindo o quarto com outras pessoas, conviveu com a prostituição nas pensões e confessa que algumas situações o levaram a ter ciúmes, ódio, "vontade de matar alguém", mas sua fama sempre foi de pessoa tranquila. Quino lembra algumas tirinhas com outros personagens e comenta no caso do filho da velha que lembra a frase da mãe que nunca o abandonará, que o faz pensar na "desilusão que azeda os casais; o abuso de poder que esfria as relações com pais e professores; a guerra e a fome como expressão extrema da miséria humana" (CF. GUERRIERO, 2014).

Freire $(2014$, p. 48) ressalta sobre a importância de ensinar a ler o mundo e também a indignação contra as injustiças, nesse sentido, a criança pode contribuir muito para compreender as questões éticas, quando devidamente preparada para ser educada e saber discutir, participar, dar a sua opinião, revelar o seu conhecimento, as suas dúvidas e dificuldades e os seus 
sentimentos para consigo e o próximo, porque uma prática educativa libertadora é para Freire uma prática de valorização dos sentimentos das crianças na relação com o outro, com o mundo e a vida.

\section{ANÁLISE DOS DEZ PRINCÍPIOS OU DIREITOS DA CRIANÇA E A DEFESA DE UMA EDUCAÇÃO ÉTICO-ESTÉTICA}

Dadas as considerações sobre o criador da Mafalda e o contexto de sua vida e obra, discutiu-se algumas considerações sobre a questão ética na educação das crianças, segue uma leitura e análise da Declaracion de los direchos del niño, ou simplesmente, os Dez Princípios em Quino ( TEJóN, 1977) pautados por uma educação ética, pela sensibilidade e uma razão criativa, que estamos considerando como sendo uma razão pautada pela curiosidade e a criatividade de acordo com material de análise, as dez tirinhas do artista sobre os Direitos da Criança.

Princípio 1 - El niño disfrutara de todos los derechos enunciados en esta Declaración. Estos derechos serán reconocidos a todos los niños sin excepción alguna ni distinción o discriminación por motivos de raza, color, sexo, idioma, religión, opiniones políticas o de otra índole, origen nacional o social, posición económica, nacimiento u otra condición, ya sea del propio niño o de su familia.

O primeiro princípio trata dos elementos fundamentais que podem assegurar uma Declaração dos direitos da criança. Direitos que devem ser reconhecidos, discutidos, refletidos e consolidados a fim de garantir à criança o direito de ser criança, de viver de maneira digna, livre e democraticamente. Esse princípio, na visão do artista contribui para fazer valer os direitos das crianças mediante uma Declaração - podendo-se discutir como garantir que todas as crianças possam viver sem discriminação, sem preconceito, sem violência de qualquer natureza contra a criança e sua potência de vida. E ainda que pareça algo utópico, é fundamental considerar que não compete à educação eliminar os sonhos e os devaneios, elementos fundamentais na formação da sensibilidade da criança.

Todas as crianças serão reconhecidas como sujeitos de direitos, sem exceções, sem distinções e sem discriminações, sejam de "raça, cor, sexo, idioma, religião, opiniões políticas ou de outra índole, origem nacional ou social, posição econômica, nascimento ou outra condição, que seja da própria criança ou de sua família". Este primeiro princípio abre um painel fundamental sobre os direitos básicos que devem ser garantidos aos seres humanos desde a fase infantil, o que poderá incidir na compreensão dos direitos dos adultos, enquanto pessoas humanas, que foram educadas para a convivência e a troca de conhecimentos, para praticar as gentilezas, os afetos e o respeito à vida. O que significa dizer que nenhum elemento dos que aqui foram apresentados $\mathrm{e}$ outros que não foram assinalados pelo autor, não devem ser tolerados, especialmente quando forem usados para discriminar, rotular ou negligenciar a criança e seu mundo de criança junto aos adultos responsáveis direta ou indiretamente por ela.

O segundo princípio aponta para os elementos que podem garantir proteção e oferecer condições que oportunizem o desenvolvimento da criança de maneira plena e democrática: 
Princípio 2 - El niño gozará de una protección especial y dispondrá de oportunidades y servicios, dispensado todo ello por la ley y por otros medios, para que pueda desarrollarse física, mental, moral, espiritual y socialmente en forma saludable y normal, así como en condiciones de libertad y dignidad. Al promulgar leyes con este fin, la consideración fundamental a que se atenderá será el interés superior del niño.

A proteção especial deve ser entendida como o cuidado com a criança e sua infância por parte da família, dos cuidadores, dos educadores, dos que ensinam e educam, que despertam e reforçam sua sensibilidade e religiosidade, quer seja em casa ou nos templos de doutrinação, devem ser feitos com cuidado e em condições de liberdade e dignidade, ou seja, sem constranger, sem ofender ou humilhar a criança e sem forçá-la, o que significa que é fundamental dialogar com a criança sobre os lugares que ela frequentará e porque aqueles lugares foram escolhidos pelos seus responsáveis almejando atingir sua inteligência de maneira livre, esclarecida, consentida e dialógica.

O terceiro princípio diz respeito a garantia do direito da criança de ter um nome e uma nacionalidade, como segue: Princípio 3 - "El niño tiene derecho desde su nacimiento a un nombre y a una nacionalidade". Uma questão que parece simples, mas na atualidade, ela tem sido uma questão complexa, dadas as mudanças de emprego, de cidade, de trabalho, de horários, o deslocamento constante de pessoas de um lugar para outro por questões de trabalho, por falta de condições de permanecer no lugar de nascimento - país de origem, pelas situações de guerra e outros tipos de conflitos. Contudo, nada disso pode ser considerado um impedimento para o cuidar e o zelar pela vida da criança.

O quarto princípio diz respeito aos benefícios e a seguridade social para as crianças.

Princípio 4 - El niño debe gozar de los beneficios de la seguridad social. Tendrá derecho a crecer y desarrolarse en buena salud; con este fin deberán proporcionarse, tanto a él como a su madre, cuidados especiales, incluso atención prenatal y posnatal. El niño tendrá derecho a disfrutar de alimentación, vivienda, recreo y servicios médicos adecuados.

Direito de viver e conviver em lugares que não ferem a saúde integral da criança, também os cuidados especiais para aqueles que lidam com elas, como as mães/pais ou outros responsáveis por elas. No caso das mães, vale lembrar que é fundamental um acompanhamento na gestação e após o nascimento da criança, que não lhes falte alimentos, vestuário, diversão e acompanhamento médico.

O quinto princípio trata de problemas que possam causar impedimentos ao desenvolvimento integral da criança ou que possa dificultar seu desenvolvimento físico, psíquico ou social, devendo por isso, receber tratamento especial equivalente ao tipo de problema ou situação particular, e que não lhe falte educação, como segue: Princípio 5 - “El niño física o 
mentalmente impedido o que sufra algún impedimento social debe recibir el tratamiento, la educación y el cuidado especiales que requiere su caso particular".

É fundamental considerar que no Brasil a taxa de analfabetismo de jovens com cerca de quinze anos, está estre 3.9\% a 13,9\% em território nacional (IBGE, 2017), ou seja, é preciso um trabalho que incentive e oportunize crianças e adolescentes no Brasil a frequentar a escola como parte de sua cidadania e do direito a se preparar para o futuro.

O sexto princípio trata do desenvolvimento da personalidade, cujos suportes são o amor e a compreensão.

Princípio 6 - El niño, para el pleno y armonioso desarrollo de su personalidad, necesita amor y comprensión. Siempre que sea posible, deberá crecer al amparo y bajo la responsabilidad de sus padres y en todo caso, en un ambiente de afecto y de seguridad moral y material; salvo circunstancias excepcionales, no deberá separarse al niño de corta edad de su madre. La sociedad y autoridades públicas tendrán la obligación de cuidar especialmente a los niños sin familia o que carezcan de medios adecuados de subsistencia. Para el mantenimiento de los hijos de familias numerosas conviene conceder subsidios estatales o de otro índole.

Que não falte à criança o amparo e a afetividade, a segurança material e moral, que não se separe das pessoas que representam sua segurança, que a sociedade, entenda-se os órgãos governamentais cuidem das crianças órfãs e lhes provenham os meios adequados para garantir o desenvolvimento de sua personalidade, bem como, a necessidade de amparo quando se trata de famílias numerosas.

No Brasil, com relação aos direitos humanos das crianças e adolescentes, conforme Vilela (2019), do site Agencia Brasil:

'Há uma cultura dos maus-tratos no país, e a gente precisa implementar a cultura dos bons tratos às crianças e aos adolescentes, os bons tratos em família', afirma Petrúcia de Melo Andrade, secretária nacional dos Direitos da Criança e do Adolescente do Ministério da Família, Mulher e Direitos Humanos. A secretária cita o Estatuto da Criança e do Adolescente para ressaltar a responsabilidade da família nos cuidados dos menores de idade, e pede maior envolvimento. (VILELA, 2019).

O sétimo princípio trata dos direitos da criança no que tange a instrução pela educação.

Princípio 7 - El niño tiene derecho a recibir educación que será gratuita y obligatoria por lo menos en las etapas elementales. Se le dará una educación que favorezca su cultura general y le permita, en condiciones de iguldad de oportunidades, desarrollar sus aptitudes y su juicio individual, su sentido de responsabilidad moral y social, llegar a ser un miembro útil de la sociedad. El interés superior del niño debe ser el principio rector de quienes tienen la responsabilidad de su educación y orientación; dicha responsabilidad 
incumbe en primer término, a sus padres. El niño debe disfrutar plenamente de juegos y recreaciones, los cuales deberán estar orientados hacia los fines perseguidos por la educación; la sociedad y las autoridades públicas se esforzarán por promover el goce de este derecho.

Mas educação deve ser entendida como aquela de boa qualidade, gratuita e obrigatória para todas as crianças nas etapas que são fundamentais, garantir que os valores de sua cultura sejam respeitados e que a criança tenha acesso à cultura geral, receba uma educação crítica e emancipadora, uma educação ética no sentido de tornar-se um ser social e moral e ser responsável pela educação que está recebendo, bem como os seus responsáveis perante a lei.

O oitavo princípio trata de garantir que em situações emergenciais a criança seja uma das primeiras a serem atendidas e socorridas: Princípio 8 - "El niño debe, en todas las circunstancias, figurar entre los primeros que reciban protección y socorro".

Este princípio atualmente é relevante e emergencial por se tratar de proteção à milhares de crianças que se encontram à margem da sociedade, seja por questões capitalistas que fazem emergir problemas econômicos, sociais, culturais e financeiros, que abalam as estruturas organizacionais que já se encontram despreparadas para o emergencial, o contraditório o que não pode eticamente ser ignorado ou esperar por uma solução, a infância é uma etapa da vida que não espera e nem pode esperar por soluções futuras, como os genocídios de populações indígenas, de crianças indígenas, crianças negras e em geral de criança pobre, desvalida.

O nono princípio trata da garantia de assistência à criança em condições de abandono, crueldade ou exploração.

Princípio 9 - El niño debe ser protegido contra toda forma de abandono, crueldad y explotación. No será objeto de ningún tipo de trata. No deberá permitirse al niño trabajar antes de una edad mínima adecuada; en ningún caso se le dedicará ni se le permitira que se dedique a ocupación o empleo alguno que pueda perjudicar su salud o su educación, o impedir su desarrollo físico, mental o moral.

A criança não pode em hipótese alguma ser alvo ou objeto de nenhum tipo de tratamento como estes que estão descritos neste princípio, não sendo considerada capaz de trabalhar sem uma idade mínima para isso, especialmente, quando as situações citadas e as do trabalho lhe impedem de desenvolver-se fisicamente, mentalmente e moralmente. Na atualidade, infelizmente, é sabido que o trabalho infantil não deixou de existir. O que certamente é um problema econômico, mas também ético.

O décimo princípio trata de proteger a criança de qualquer tipo de prática humana ou social, cultural que fomente ou que possa fomentar sua discriminação. 
Princípio 10 - El niño debe ser protegido contra las prácticas que puedan fomentar la discriminación racial, religiosa o de cualquiera otra índole. Debe ser educado en un espíritu de comprensión, tolerancia, amistad entre los pueblos, paz y fraternidad universal, y con plena conciencia de que debe consagrar sus energías y aptitudes al servicio de sus semejantes.

Este princípio declara que sempre deve prevalecer o espírito de tolerância e de amizade por todos os povos numa fraternidade universal em prol dos semelhantes, garantindo com isso a diversidade, a diferença e os elementos que subjazem em sua identidade como pessoa humana.

\section{CONSIDERAÇÕES FINAIS}

Acreditamos que não somente no Brasil, mas especialmente na América Latina, a leitura da obra de Quino, no que tange a infância, a criança e a educação é fundamental, por tratar-se de uma educação norteadora no sentido ético e estético, uma razão criativa e questionadora, cujo protagonista é a criança com sua razão sensível e criativa para dialogar com o adulto e com ele aprender, trocar e ensinar, numa via de mão dupla no sentido de Paulo Freire $(2013,2014,2015)$

Destarte, os dez princípios na obra de Quino, se levados a sério no processo de formação humana, na educação da criança, dentro e fora do lar, dentro e fora da escola e nas sociedades nas quais elas circulam, trocam e aprendem, é um documento que favorece a compreensão das crianças sobre os direitos que tangem o seu desenvolvimento humano, pode ajudar os órgãos responsáveis pelas diretrizes educacionais e de seguridade sobre a criança, contribuir para que pessoas de todos os lugares do mundo se juntem em prol da infância e do direito da criança de ser tratada com dignidade, com ética e respeito, considerando-a um ser humano em formação, mas não como um ser humano desprovido de formação, delineia portanto os elementos fundamentais sobre o mundo da criança e o que lhes cerca, de maneira reflexiva e em prol dela.

O capitalismo não pode no sentido de Walter Benjamin (2013) ou no sentido de Zigmut Bauman (1998) nortear todo o fazer e o saber sobre a vida, a educação e o aprendizado em sociedade, determinar o aniquilamento da vida como se ela fosse um simples objeto ou produto do capital com prazo de duração e validade. É fundamental pensar nos direitos da criança de poder expressar seus sentimentos, suas dúvidas, dificuldades e afetos. Sendo portanto, fundamental discutir sobre material formativo, como a Declaracion de los direchos del niño apontados por Quino (TEJÓN, 1977), objetivando a sensibilidade da criança e do adulto para a formação de uma consciência de infância no que tange aos direitos e deveres da criança cidadã, que vive, luta, aprende e acima de tudo age de acordo com uma ética do vivente, que lhe fortalece o caráter e dignifica a vida.

\section{REFERÊNCIAS}

ABBAGNANO, Nicola. Dicionário de Filosofia. Tradução de Alfredo Bosi, revisão e tradução de novos textos de Ivone Castilho Benedetti. São Paulo: Martins Fontes, 2000.

BAUMAN, Z. O mal-estar da pós-modernidade. Rio de Janeiro: Jorge Zahar Editor, 1998.

BENJAMIN, Walter. Reflexões sobre a criança, o brinquedo e a educação. Trad., apresentação e notas Marcus Vinicius Mazzari. São Paulo: Duas cidades /Editora 34, 2002. 
BENJAMIN, Walter. Rua de mão única. Trad. Rubens Rodrigues Torres Filho e José Carlos Martins Barbosa. São Paulo: Brasiliense, 2009.

BENJAMIN, Walter. O capitalismo como religião. Org., Michael Lowy; trad. Nélio Schneider. São Paulo Boitempo, 2013

BENJAMIN, Walter. A hora das crianças: narrativas radiofônicas. Trad. Aldo Medeiros. Rio de Janeiro: Nau editora, 2015.

FREIRE, Paulo. A importância do ato de ler: em três artigos que se completam. 51. ed. 2.

reimpressão. São Paulo: Cortez, 2013.

FREIRE, Paulo. Pedagogia da indignação: Cartas pedagógicas e outros escritos. São Paulo: Paz e Terra, 2014.

FREIRE, Paulo. Pedagogia dos sonhos possíveis. São Paulo: Paz e Terra, 2015.

FREIRE, Paulo. Pedagogia da autonomia: Saberes necessários à pratica educativa. Rio de Janeiro, São Paulo: 2018.

GUERREIRO, Leila. Quino, o mestre da tira. Jornal El País. Disponível em: $<$ https://brasil.elpais.com/brasil/2014/10/17/sociedad/1413566259 284551.ht $>$. Acesso em 20/05/2017.

SCHOLEM, Gershom. Walter Benjamin: A história de uma amizade. Tradução de Geraldo G. de Souza, N. Norbert Zins e J. Guinsburg. São Paulo: Perspectiva, 1989.

TEJÓN, Joaquín Salvador Lavado (Quino). Declaracion de los direchos del niño, 1977. Disponível em: <http://mafalda.dreamers.com/Especiales/derechos.htm>. Acesso em 20/05/2017.

MI BUENOS AIRES QUERIDO.COM. Disponível em:

<http://www.mibuenosairesquerido.com/pt/personalidades-argentinas/quino-mafalda/>. Acesso em 20/05/2017.

VILELA, Pedro Rafael. Mais de $\mathbf{7 0 \%}$ da violência sexual contra crianças ocorre dentro de casa.

Disponível em: < http://agenciabrasil.ebc.com.br/direitos-humanos/noticia/2019-05/mais-de-70da-violencia-sexual-contra-criancas-ocorre-dentro-de>. Acesso em 06/06/2019. 